\title{
RUPTURA E REENCONTROS ENTRE CARTOGRAFIA E ARTE E SEUS DESDOBRAMENTOS NA EDUCAÇÃO GEOGRÁFICA CONTEMPORÂNEA ${ }^{1}$
}

\author{
RUPTURE AND BREAKDOWNS BETWEEN CARTOGRAPHY AND ART \\ AND ITS DEVELOPMENTS IN CONTEMPORARY GEOGRAPHICAL \\ EDUCATION
}

\author{
RUPTURA Y REENCUTEROS ENTRE CARTOGRAFÍA Y ARTE Y SUS \\ DESARROLLOS EN LA EDUCACIÓN GEOGRÁFICA CONTEMPORÁNEA
}

\author{
Gisele Girardi ${ }^{2}$ \\ Universidade Federal do Espírito Santo, Vitória, Brasil
}

Resumo: A incorporação parcial de conhecimentos cartográficos no âmbito da cultura geográfica escolar brasileira promoveu um enrijecimento nas formas de se produzir geografia com mapas. Uma das possibilidades de entendimento da cartografia e dos mapas tem sido considerada a única possível, o que está na origem do forte caráter prescritivo que assumiu o conteúdo cartográfico no âmbito escolar. Serão analisados elementos da origem e disseminação de uma estética utilitária para os mapas que sustenta o referido enrijecimento, bem como serão apresentadas algumas discussões atuais sobre cartografia e arte que possam contribuir com o necessário repensar da cartografia na educação geográfica contemporânea.

Palavras-chave: Cartografia geográfica; arte; educação geográfica.

Abstract: The partial incorporation of cartographic knowledge in the Brazilian geographic scholar culture fostered a stiffness in ways to produce geography with maps. One of the possibilities for understanding of cartography and maps has been considered the only possible, which is in the origin of the strong prescriptive character that took the cartographic content in schools. We will analyze elements of the origin and spread of a utilitarian aesthetic to the maps that sustains the quoted stiffness, and will present some current discussions about cartography and art that can contribute to the necessary rethinking of the contemporary cartography in geographical education.

Keywords: Geographic cartography; art; geographic education.

Resumen: La incorporación parcial del conocimiento cartográfico en la cultura escolar geográfica brasileña, promovió una rigidez en la forma de producir geografía con mapas. Una de las posibilidades para la comprensión de la cartografía y los mapas ha sido considerada como la única posible, y esto está en el origen de lo fuerte carácter prescriptivo que tomó el contenido cartográfico en las escuelas. Vamos a analizar los elementos del origen y propagación de una estética utilitaria de los mapas que sostiene la rigidez citada, y se presentarán algunas de las discusiones actuales sobre la

\footnotetext{
${ }^{1}$ Integra o Projeto "Imagens, Geografias e Educação". Financiamento 2012-2013 - CNPq, Processo 477376/2011-8.

2 Grupo de pesquisa CNPq POESI - Política Espacial das Imagens Cartográficas. E-mail: gisele.girardi@pq.cnpq.br.
} 
cartografía y el arte que pueden contribuir con el necesario repensamiento de la cartografía en la educación geográfica contemporánea.

Palabras clave: Cartografía geográfica; el arte; la educación geográfica.

\section{INTRODUÇÃO}

De todas as especializações temáticas que compõem o campo da ciência geográfica é, seguramente, na cartografia que a referência à arte parece ser inquestionável. Essa conexão adveio da visualidade inerente às produções cartográficas, mas também do ofício, em especial em tempos mais remotos, quando habilidades e técnicas manuais que a produção de mapas demandava se aproximavam muito daquelas empregadas pelos artistas. Nos dias atuais, com a disseminação das geotecnologias e também com a virada cultural na Geografia, retomam-se as conexões e os "projetos disciplinares da geografia e da arte, tradicionalmente separados, sobrepoem-se e convergem de forma emocionante, e em nenhum lugar isso é mais diretamente expresso que no trabalho com mapas" (COSGROVE, 2008, p. 178, tradução nossa).

O mapa é o produto de um saber-fazer. Podemos localizar, no decurso da história da humanidade, desde os primórdios, produções que podem ser identificadas como mapas (LEWIS, 1987; HARLEY, 1987, 1991). Contudo, a referência de cultura visual que temos como mapa, até os dias de hoje, surgiu no contexto da emergência do Estado moderno, do desenvolvimento das relações capitalistas e do pensamento científico cartesiano e essas referências se tornaram inextricáveis à atividade cartográfica (WOOD, 2010). É neste contexto histórico mais amplo que se situa a origem da Geografia institucionalizada, que tanto teve a produção cartográfica como elemento fundante, como incorporou a linguagem cartográfica no âmbito dos seus fazeres próprios.

Até meados do século $\mathrm{XX}$, a atividade de produção cartográfica estava prioritariamente nas mãos das forças armadas e dos estados, dada sua tarefa de conhecimento e controle dos territórios nacionais. Isto no que se refere aos levantamentos básicos ou topográficos. Já o desenvolvimento de produtos cartográficos outros, como os mapas temáticos e o desenvolvimento das técnicas para sua elaboração 
se localizava, neste mesmo período, em grande medida, nas instituições geográficas, acadêmicas ou governamentais.

O ensino de Geografia na escolarização formal também tem origem no contexto do fortalecimento dos Estados-nação e foi este o lugar privilegiado para a educação cartográfica, de tal modo que nesta está hoje profundamente arraigada a noção de mapa como imagem racional e o território político administrativo como imagem privilegiada destas produções, conforme discute Oliveira Jr. (2011).

Esta breve contextualização tem o propósito de situar a discussão que aqui se propõe. A linha central da argumentação deste texto é que houve uma incorporação parcial de conhecimentos cartográficos no âmbito da cultura geográfica escolar, promovendo, ao menos no caso brasileiro, certo enrijecimento nas formas de se produzir geografia com mapas. $\mathrm{O}$ enrijecimento ao qual nos referimos é a apropriação de uma possibilidade de trabalho com a cartografia como se fosse a única possível, o que está na origem do forte caráter prescritivo que assumiu o conteúdo cartográfico no âmbito escolar. Estas prescrições, reveladas em afirmações tais como "mapa tem que tem rosa dos ventos", "mapa tem que ter escala" e tantas outras, tem trabalhado para afirmar um modo específico de conceber mapas.

Muitos documentos oficiais que lidam com orientações, diretrizes e parâmetros para o ensino de Geografia assumem a cartografia como linguagem essencial para este campo do saber, mas, ao mesmo tempo, apresentam um entendimento parcial desta linguagem. São muitos os fatores que contribuem para que se entenda esta situação, já discutidos por Girardi (2004) e Fonseca (2007), e não é o propósito deste texto aprofundá-los.

O ponto que será enfocado neste trabalho é o da origem e disseminação de uma estética utilitária para os mapas que hoje se desdobra no ensino de Geografia como a única possível. Serão também apresentadas algumas discussões atuais sobre cartografia e arte que possam lançar algumas luzes ao necessário repensar a cartografia na educação geográfica contemporânea.

\section{EMERgÊNCIA (E PERMANÊNCIA) DE UMA ESTÉtiCA PARA OS MAPAS}

O contexto da Segunda Guerra Mundial colocou problemas novos para a cartografia. As formas de produção cartográfica até então criadas e utilizadas foram 
postas em xeque, especialmente no que se referia à geração de mapas suficientemente claros e que permitissem leitura rápida para instruir tomadas de decisão. O modo com que os geógrafos de então trabalhavam com a cartografia no âmbito da geografia era aquela herdada dos estudos regionais, acrescida dos aparatos e produtos que os desenvolvimentos tecnológicos disponibilizavam, como a fotografia aérea, por exemplo. Não havia, portanto, expertise por parte dos geógrafos para este tipo de mapa demandado pela Guerra. Não era um problema de fonte de informação, mas de modo de apresentação, ou seja, de design cartográfico, de uma estética de mapa.

A busca de solução para estas questões cartográficas demandadas pela Segunda Guerra não cessou com o fim do conflito, mas proliferou nos âmbitos em que os cartógrafos se engajaram posteriormente. Conforme apontam Barnes (2006) e Crampton (2011), esta situação é bem ilustrada no caso estadunidense, com os esforços daquele país na estruturação de uma inteligência cartográfica vinculada ao conflito bélico. Atribui-se a Arthur Robinson o legado de um modo de pensar a cartografia: "uma aplicação objetiva das melhores práticas de design" (PERKINS et al, 2011, p. 194, tradução nossa). A subjetividade ou traços de autoria, que eram evidentes nas produções cartográficas até meados do Século XX não cabiam neste novo modo. Do mesmo modo a arte, que, para Robinson, poderia levar a decisões arbitrárias sobre o design do mapa, o que prejudicaria a sua eficiência comunicativa (PERKINS et al, 2011).

Robinson formulou esta concepção de mapa como imagem objetiva a partir de sua experiência na Divisão de Mapas do Setor de Pesquisas e Análises (R\&A Research and Analysis Branch) do Escritório de Serviços Estratégicos (OSS - Office of Strategic Services) dos Estados Unidos (antecessor da CIA - Central Intelligence Agency), a qual presidiu no período da Segunda Guerra Mundial. Petchenik (1983) apontou que esta experiência foi fundamental para o desenvolvimento da pesquisa em design de mapas a partir de então, situando o livro "The look of maps", de Robinson, publicado em 1952, como a origem da prática da cartografia científica, que objetivaria o mapa ótimo do ponto de vista da transmissão da informação, envolvendo pesquisas de estímulo-resposta.

A criação da Associação Cartográfica Internacional em 1959 significou um campo de disseminação destas ideias acerca do design cartográfico, assim como promoveu debates acerca de teorias para esta "nova" ciência. A pauta teórica central passou ser a comunicação por mapas e, portanto, a eficiência do produto na transmissão da informação. A comunicação cartográfica difere do design cartográfico na medida em 
que a primeira pressupõe um sujeito a ser conhecido para adequação do mapa à suas possibilidades e no segundo o leitor do mapa é abstrato ou tomado como um coletivo homogêneo e acrítico. O trabalho seminal desta perspectiva é o de Koláčný, que elaborou um modelo de transmissão da informação cartográfica (Figura 1), no qual considerava o conteúdo, o design e o uso do mapa como partes de um mesmo processo.

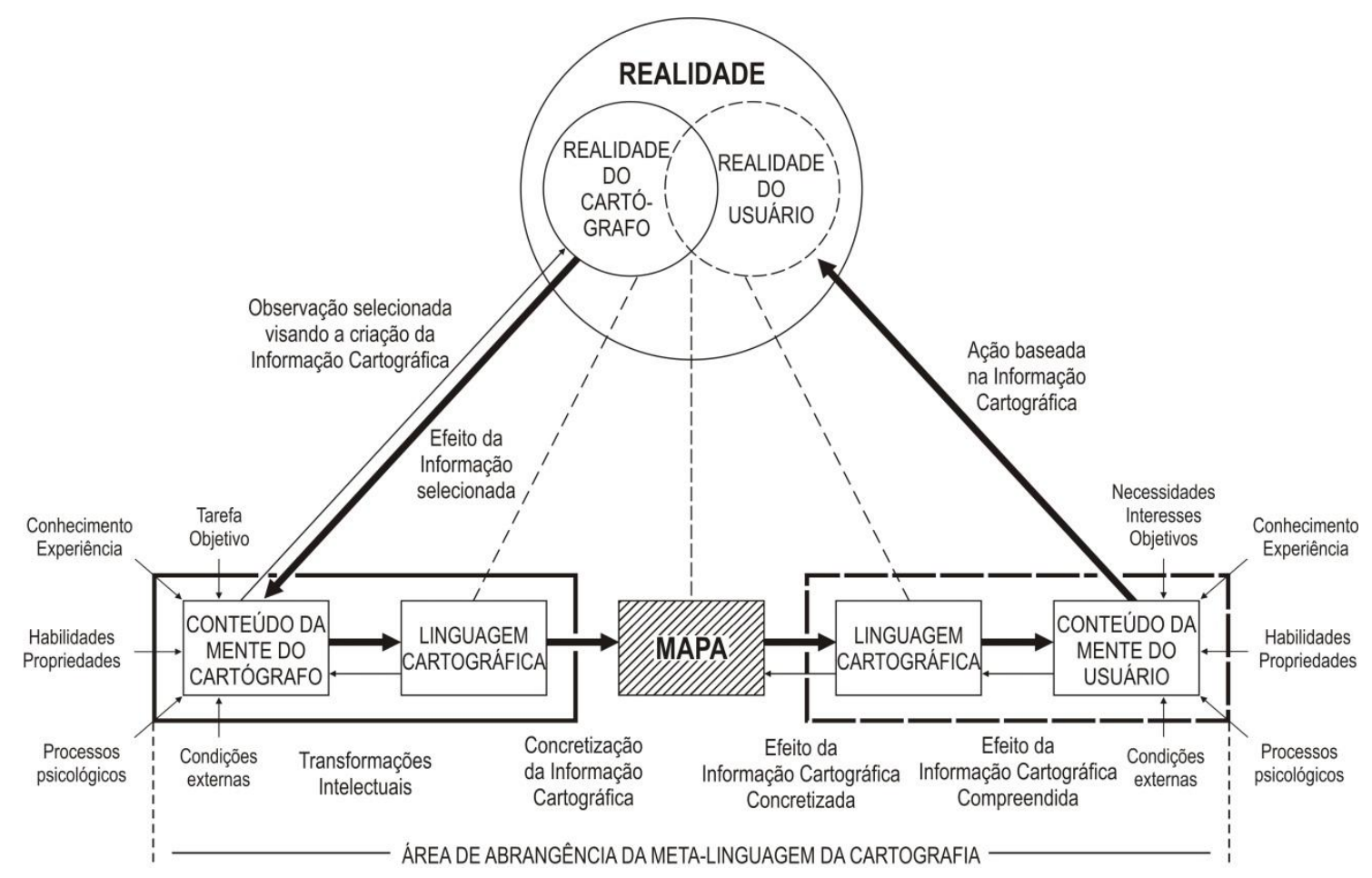

Figura 1 - Comunicação da informação cartográfica, cf. Koláčný, 1967 (KOLÁČNÝ, 1977, p. 41; traduzida por SIMIELLI, 1986, p. 45).

Este modelo leva em consideração o trajeto da informação que tem como ponto de partida e de chegada a "realidade", ou mais precisamente, o compartilhamento de ideias parciais acerca da realidade entre dois sujeitos ideais, o cartógrafo e o usuário do mapa. Observa-se que no modelo há interferências de várias naturezas em todas as etapas da transmissão da informação. Nos dois sujeitos ideais considerados há uma série de fatores atuantes, como necessidades, propósito, objetivo, conhecimento, experiência, habilidades, competências, processos psicológicos, condições externas... Contudo, todos estes fatores, na perspectiva do modelo, deveriam ser controlados. Por este motivo, questões sobre a arte não caberiam, pois a apreciação estética, sendo "um assunto tão tênue, é um elemento difícil de incorporar em modelos mecanicistas da atividade humana" (KEATES, 1984, p. 37, tradução nossa). 
Ao design de mapas e aos modelos de comunicação cartográfica, corroborou a semiologia gráfica (PALSKY, 2011). Esta se diferencia das anteriores, pois não admite um processo de transmissão de informações, mas o compartilhamento da mesma racionalidade, amparada no visual, entre os atores do processo cartográfico. Neste sentido, Bertin considera que "a cartografia é uma linguagem universal", (BERTIN, 1988, p. 50), destinada ao olho e monossêmica, ou seja, comporta somente um significado. Em várias passagens de seus textos, Jacques Bertin reafirma o caráter racional da imagem cartográfica e refuta qualquer possibilidade de ruídos advindos ou de convenções ou da arte, como no trecho a seguir: "Não se olha uma carta como se olha uma obra de arte. Faz-se perguntas a uma carta" (BERTIN, 1988, p. 47). Para este autor, qualquer leitor tem o direito de fazer duas perguntas diante de um mapa ou carta: a elementar, "em tal lugar, o que há?" e a de conjunto "tal elemento, qual é sua geografia?" A obra de Bertin representa, indubitavelmente, o mais vigoroso manual de elaboração de imagens racionais (mapas, diagramas e redes). Mas, é bom que se insista neste ponto, esta é uma das possibilidades para a cartografia, e não a única.

São, em geral, muito raros trabalhos que discutem a arte neste período de predomínio da racionalidade na construção da imagem cartográfica, como é o caso do artigo de Keates (1984), que, com apoio em alguns filósofos e estudiosos de arte, apresentou um panorama sobre o que seria a apreciação estética em mapas. Keates criticava o reducionismo comunicativo dos mapas e afirmava que eles têm também possibilidades artísticas:

[...] quero chamar a atenção para o fato de que existem domínios da experiência humana que não são - e nunca serão - produtos da ciência; e embora pouco de nós possa aspirar criar [mapas com arte], nós podemos - e devemos - apreciá-los (KEATES, 1984, p. 43 Tradução nossa).

$\mathrm{Na}$ última década do século $\mathrm{XX}$, a cartografia científica se manteve fundamentada no paradigma da comunicação cartográfica, agora incorporado ao campo tecnológico, compondo o novo paradigma da visualização cartográfica (para o qual a comunicação é a última etapa a ser considerada, conforme MacEachren [1995]). Mas Crampton (1992) apontou que mesmo este novo paradigma ignora a grande parte da produção cartográfica feita pela sociedade em todo o mundo, pois prescreve um modo único de validação da produção cartográfica. Este autor chamou a atenção para a necessidade de a comunidade cartográfica profissional e acadêmica levar em 
consideração a pluralidade de produções cartográficas, o que denominou de "cartografias alternativas". Para este autor

A abordagem alternativa para a cartografia, então, não é prescritiva, não diz que há uma maneira única de realizar a cartografia, mas que há muitas maneiras, algumas adaptadas a algumas ocasiões e algumas adaptadas a outras. Isso, por si só, é uma crítica ao impulso científico de grande parte da cartografia atual, que em suas formas extremas não reconhece a validade da cartografia não-científica. Cartografias alternativas desejam evitar o erro de prescrever qualquer abordagem única, como a abordagem científica tem feito, e argumenta que a cartografia deve ser sensível ao contexto (CRAMPTON, 1992, p. 147, tradução nossa).

A cartografia do século XXI apresentou um vertiginoso aumento no acesso a bases cartográficas e de dados e de imagens de sensoriamento remoto, advindos da abertura democrática ou da descolonização em vários países do mundo, da ampla disseminação da internet e, com ela, possibilidades tanto de acesso como de produção de mapas colaborativos, por meio de software livres e de fontes abertas, bem como apropriações diversas da cartografia, como, por exemplo, por artistas. Sobre este contexto, Crampton e Krygier (2006) afirmam que

Hoje, principais cartógrafos acadêmicos já superaram os princípios fundamentais da cartografia robinsoniana. Por exemplo, a maioria já aceita que o modelo de comunicação cartográfica já não é uma explicação adequada de como os mapas trabalham [...] a geovisualização expandiu sua ênfase no fornecimento de informações para englobar também a sua exploração. Duas consequências disso são que o mapeamento não está mais nas mãos dos especialistas (que ainda estão perdendo espaço para a prática de hackeamento de mapas), e que o método científico de testes de hipóteses e confirmação de padrão não é mais adequado (CRAMPTON; KRYGIER, 2006, p. 24, tradução nossa).

O grande ponto de ruptura entre a cartografia e a arte se deu na proposição de mapas como imagens racionais. Por outro lado, no campo da cartografia há uma crítica e abertura crescentes na perspectiva de novas cartografias, plurais e assentadas em bases diversas. Paradoxalmente, na educação cartográfica a estética prescritiva baseada em mapas como imagens racionais é a que permanece, majoritariamente. No que se refere à Geografia, em especial à educação geográfica brasileira, que é o que interessa mais detalhadamente aqui, a permanência desta estética se descola do movimento do pensamento geográfico ou, para utilizar os termos de Moreira (2012), da linguagem conceitual da geografia. Este autor identifica a escola como um lugar de recuperação da defasagem entre a linguagem conceitual da geografia e a linguagem cartográfica, que é um problema central da geografia contemporânea: 
A solução supõe, todavia, trazer a cartografia para o seio da Geografia. A segunda ficou com o conteúdo e perdeu a forma, e a primeira levou a forma e ficou sem conteúdo. Nessa divisão de trabalho reciprocamente alienante e estranha, a cartografia virou uma forma sem conteúdo e a geografia um conteúdo sem forma. Diante de um espaço de formas de paisagens cada vez mais fluidas, a ação teórica da geografia não poderia dar senão numa pletora de desencontros: desencontro da geografia e da cartografia frente ao desencontro da forma-paisagem com o conteúdo-espaço. Faltou aí uma teoria da imagem num tempo de espaços fluidos (MOREIRA, 2012, p. 184).

Frente a esta possibilidade da escola como lugar de recuperação da defasagem entre a linguagem conceitual da geografia e a linguagem cartográfica aludida por Ruy Moreira, a questão é criar, inventar percursos pedagógicos outros. Como lugar de cultura, a escola é potencialmente aberta para experimentações que possam desacostumar o olhar e o pensamento da estética da imagem racional da cartografia, constituída a partir do Estado, e ampliar possibilidades para a linguagem cartográfica (SEEMANN, 2010; OLIVEIRA JR., 2012). De modo a contribuir com o adensamento destas ideias, será apresentado e discutido um panorama geral sobre cartografia e arte na contemporaneidade.

\section{CARTOGRAFIA E ARTE NA CONTEMPORANEIDADE}

Como visto, a emergência do paradigma da comunicação cartográfica, que predominou no debate teórico da cartografia dos anos 1960 até pelo menos os anos 1990, e o desenvolvimento das geotecnologias, marcadamente a partir dos anos 1980 resultam no desaparecimento da arte e do debate sobre ela na cartografia, com raríssimas exceções.

Um rápido olhar nas modificações das definições de cartografia da Associação Cartográfica Internacional neste período é revelador:

1966 - é o conjunto de estudos e das operações científicas, artísticas e técnicas que intervém a partir dos resultados das observações diretas ou da exploração de uma documentação, tendo em vista a elaboração de cartas, plantas e outros modos de expressão, assim como sua utilização.

1973 - a arte, a ciência e a tecnologia de fazer mapas, juntamente com seu estudo como documentos científicos e obras de arte.

1991 - a disciplina que trata da concepção, produção, disseminação e estudo de mapas. 
Na definição de 1966 as operações artísticas são intrínsecas à cartografia; em 1973 a arte é uma das possibilidades para a cartografia e os mapas podem ser considerados como obras de arte. Na definição de 1991 a arte desapareceu.

Krygier (1995), contudo, afirma que as mudanças na definição oficial não necessariamente mudam o modo como pensamos a cartografia e que a despeito de ter sido omitida desta definição, existe uma ideia de 'arte' vagamente definida nos trabalhos de cartografia, mesmo que se considere que ela tenha um papel fundamental no futuro. Este autor apresentou uma sistematização das posições, buscando avaliar como os cartógrafos estavam utilizando ideias sobre arte e ciência para falar e pensar sobre mapas e cartografia. Para o autor, uma das grandes questões não era se os cartógrafos pensavam que a cartografia seria uma arte ou uma ciência, ou uma mistura de ambas, mas que assumiam, em grande medida, o dualismo entre arte e ciência acriticamente.

Krygier, então, identificou três abordagens acerca da arte e da ciência em cartografia. Em duas delas, reconhece a forte carga do dualismo. Naquela que denomina "polarização", identifica posições que implicitamente assumem que mapas "são necessariamente o resultado de um processo 'científico' e que qualquer valor 'artístico' que possa ter deve ser separado da ciência ou ser de importância secundária" (KRYGIER, 1995, p. 5, tradução nossa). Na que denomina "progressiva" identifica os trabalhos que tentam “avaliar algumas diferenças entre 'arte' e 'ciência' que possam ajudar a estabelecer o que em um mapa ou em um gráfico pode ser considerado ‘artístico' e o que pode ser considerado 'científico"” (1995, p. 7, tradução nossa). A terceira abordagem, segundo o autor, evita o dualismo entre ciência e arte e considera a cartografia como um processo. Sobre esta última, o autor escreve que

Métodos visuais tais como a cartografia, ajudam no processo de entendimento e construção do conhecimento, na formação e clarificação idéias, e nas diferentes formas em que passamos a conhecer e re-conhecer o nosso mundo. Tal processo é culturalmente, historicamente, socialmente e politicamente contingente e sempre em evolução, produzindo novas questões, ideias e desafios que continuamente nos confrontam (KRYGIER, 1995, p. 9, tradução nossa).

Wood (2006) e Cosgrove (2008) apontaram que o grande crescimento de trabalhos de arte envolvendo mapas data do início dos anos 1990 e que um dos fatores que explica este crescimento é a igualmente crescente ubiquidade dos mapas na contemporaneidade. Caquard, Piatti e Cartwright (2009) discutem que o crescente 
aumento de práticas híbridas entre mapas e diferentes formas de arte contribuem para a flexibilização das fronteiras entre cartografia e arte, o que se tornou possível pela convergência de vários fatores: "o grande interesse em pensamento crítico em cartografia desde o final dos anos 1980, a transformação tecnológica das práticas cartográficas [...] e a maior acessibilidade ao mapeamento e às ferramentas de visualização" (CAQUARD; PIATTI; CARTWRIGHT, 2009, p. 289, tradução nossa).

Vive-se na atualidade um vigoroso movimento de aproximação e fertilização cruzada entre arte e cartografia e começam a se ampliar não só as produções híbridas a que se referem Caquard, Piatti e Cartwright (2009), mas também escritos de pesquisadores da cartografia crítica e da geografia cultural que chamam a atenção para os trabalhos nestes campos e sua contribuição para repensar a normatividade da cartografia bem como as possibilidades outras de pensamento e ação no mundo e na ciência, em especial na geografia.

Por outro lado, são relativamente raros os escritos de artistas acerca dos trabalhos artísticos com mapas. Serão brevemente apresentados dois destes raros exemplares, produzidos por artistas sobre mapa e arte, de D'Ignazio (2009) e Watson (2009). Ambas reafirmam que os últimos 30 anos foram o período de grande explosão de exposições de arte que tinham mapas como tema central.

D'Ignazio (2009) apresenta um panorama geral de como os mapas tem sido apropriados pelos artistas de mapas para suas produções, neste período:

os artistas fizeram mapas, subverteram mapas, performaram itinerários, imaginaram territórios, contestaram fronteiras, mapearam o invisível, e hackearam espaços físicos, virtuais e híbridos a título de cartografia. Vários nomes foram sugeridos para várias cepas desta intersecção: "psicogeografia", "mídias locativas", "geografia experimental", "arte site-specific", "novo gênero de arte pública", "cartografia crítica" (um pouco diferente das versões acadêmicas), e “práticas espaciais críticas" (D’INAZIO, 2009, p. 190, tradução nossa).

De acordo com a autora, as práticas artísticas contemporâneas com mapas podem ser entendidas dentro de três grandes conjuntos. No primeiro, a que a autora denomina de "sabotadores de símbolos", a iconografia visual do mapa é utilizadas para dizer de lugares, sejam eles pessoais, fictícios, utópicos ou metafóricos. O segundo conjunto é denominado de "agentes e atores" e agrega artistas e coletivos engajados com questões políticas, visando desafiar o status quo ou promover mudanças no mundo. No terceiro conjunto situam-se artistas que se utilizam de metáforas cartográficas a fim 
de dar visibilidade para territórios informacionais, grupo que denomina de "Mapeadores de dados invisíveis".

Watson (2009) analisa que vários artistas de hoje estão engajados com as noções de mapeamento dos geógrafos, e questiona: "o que acontece quando uma disciplina utiliza os idiomas ou tropos de outro, e quais são as contribuições que cada um poderia fazer para o outro, bem como para grupos além de qualquer área?" (WATSON, 2009, p. 293 - Tradução nossa). Ela aponta que as mudanças na arte ocorrem paralelamente às mudanças tecnológicas e que no caso do mapeamento isto também é verdadeiro, e há um número crescente de trabalhos que utilizam GPS, Google Maps, softwares de código aberto e outros, incentivando um maior cruzamento entre os campos da ciência cartográfica e da arte.

A este cruzamento de papéis em que cientistas estejam mais confortáveis com os aspectos criativos de seu trabalho e os artistas compreendam que contribuir para além da galeria, a filosofia contemporânea está fornecendo suporte "não apenas na desconstrução ou desclassificação de antigos edifícios epistemológicos, mas na construção de novos métodos de trabalhar e de agir, em relação uns aos outros e aos objetos e significados" (WATSON, 2009, p. 303, tradução nossa).

\section{CONSIDERAÇÕES FINAIS}

O mundo contemporâneo nos apresenta uma grande diversidade de práticas e produtos cartográficos, criadas e apropriadas por cartógrafos e não cartógrafos, artistas e não artistas. É um mundo de possíveis.

Como foi visto, os modelos prescritivos da cartografia estão sendo desafiados por esta reapropriação generalizada de mapas. Não se trata de desprezar o conjunto de produções de ideias, de técnicas, de produtos construídos no decorrer da história da cartografia. Trata-se de situá-los, de ressignificá-los, de entendê-los em suas utilidades e também em seus exageros. Concordamos com a afirmação de Cosgrove (2008) de que, paradoxalmente, tanto a disseminação das possibilidades de fazer mapas bem como as críticas da geografia aos mapas tem "simultaneamente reduzido e melhorado o lugar da cartografia dentro da geografia" (COSGROVE, 2008, p. 163, tradução nossa). Portanto, as conexões da cartografia com a arte podem oferecer possibilidades para novos olhares e criações no campo conceitual da geografia. 
A escola como espaço de produção de cultura é privilegiado para a experimentação dessas conexões e possibilidades. E mais, para entender na geografia o papel fundamental do reencontro entre a linguagem dos conceitos e a linguagem cartográfica.

Evidentemente há muito que se pensar, propor e fazer para isto. A reapropriação do poder de fazer mapas sem, necessariamente, prender-se às prescrições, bem como o entendimento da emergência e dimensão técnico-científica, histórica e política das normas e seu papel na produção de certos tipos de produtos cartográficos, talvez sejam um começo. É, no entanto, preciso cuidar para que não se substitua uma prescrição por outra. É um caminho difícil dado o peso da cultura visual dos mapas e aos pesos muito diferentes que são atribuídos ao que é artístico e ao que é técnico e científico em nossa sociedade, bem como à tendência normativa e prescritiva das práticas escolares institucionalizadas, que reverberam, todas elas, em grande parte do que hoje reconhecemos como "cartografia escolar".

Um primeiro movimento poderia ser a incorporação na formação docente destas perspectivas contemporâneas da relação arte-cartografia-geografia, de modo a fazer mapas derivarem na produção de novos pensamentos e novas práticas espaciais (OLIVEIRA JR., 2012). “O que está em jogo é a natureza do mundo em que queremos viver" (WOOD, 2006, p. 10, tradução nossa).

\section{AGRADECIMENTOS}

Aos membros do Grupo de Pesquisa CNPq-POESI - Política Espacial das Imagens Cartográficas, pela leitura, discussão e contribuições a esse texto, em especial a André Azoury Vargas e Lorena Marinho Aranha.

\section{REFERÊNCIAS}

BARNES, Trevor J. Geographical Intelligence: American Geographers and Research and Analysis in the Office of Strategic Services 1941-1945. Journal of Historical Geography, n. 32, p. 149-168, 2006.

BERTIN, Jacques. Ver ou ler: um novo olhar sobre a Cartografia. Seleção de Textos, São Paulo, n. 18, p. 45-53, 1988.

CAQUARD, Sébastien; PIATTI, Barbara; CARTWRIGHT, William. Editorial: Special Issue on Art \& Cartography. The Cartographic Journal, v.46, n.4, p. 289-291, 2009. 
COSGROVE, Denis. Cultural cartography: maps and mapping in cultural geography. Annales de géographie, v.2, n. 660-661, p. 159-178, 2008.

CRAMPTON, Jeremy. New directions in the information era - a reply to Taylor (1991). The Cartographic Journal, v. 29, p. 145-150, 1992.

CRAMPTON, Jeremy. Arthur Robinson and the creation of America's first spy agency. In: INTERNATIONAL CARTOGRAPHIC CONFERENCE, 25, 2011. Paris, Proceedings 25 ICC, Paris, 2011. CD-ROM.

CRAMPTON, Jeremy; KRYGIER, John. An introduction to critical cartography. $A C M E$ : An international e-journal for critical geographies, v. 4, n.1, p.11-33, 2006.

D'IGNAZIO, Catherina. Art and cartography. In: KITCHIN, Rob; THRIFT, Nigel (Eds.). International Encyclopedia of Human Geography. Oxford: Elsevier, 2009, v. 1, p. 190-206.

FONSECA, Fernanda Padovesi da. O potencial analógico dos mapas. Boletim Paulista de Geografia, São Paulo, n. 87, p. 85-110, 2007.

GIRARDI, Gisele. A cartografia na geografia brasileira a partir dos anos 1970: notas para a compreensão de uma situação ainda a ser superada. In: CONGRESSO BRASILEIRO DE GEÓGRAFOS, 6, 2004. Goiânia. Anais do VI CBG. Goiânia: AGB, 2004. CD-ROM.

HARLEY, John Brian. A nova história da cartografia. O Correio da Unesco, São Paulo, v. 19, n. 8, p. 4-9, 1991.

HARLEY, John Brian. The map and the development of the History of Cartography. In: HARLEY, John Brian; WOODWARD, David (Eds.). The History of Cartography: Cartography in Prehistoric, Ancient, and Medieval Europe and the Mediterranean, v. 1, cap. 1, p. 1-42, 1987.

KEATES, John S. The cartographic art. Cartographica, v. 21, n. 1, p. 37-43, 1984.

KOLÁČNÝ, Antonín. Cartographic information: concepts and terms in modern cartography. Cartographica, n. 21, p. 39-45, 1977.

KRYGIER, John. Cartography as an art and a science? The Cartographic Journal, v. 32, p. 3-10, 1995.

LEWIS, G. Malcolm. The origins of cartography. In: HARLEY, John Brian; WOODWARD, David (Eds.). The History of Cartography: Cartography in Prehistoric, Ancient, and Medieval Europe and the Mediterranean, v. 1, cap. 3, p. 50-53, 1987.

MacEACHREN, Alan. M. How maps work: representation, visualization, and design. New York, The Guilford Press, 1995. 513p.

MOREIRA, Ruy. Geografia e práxis: a presença do espaço na teoria e na prática geográficas. São Paulo: Contexto, 2012. 221 p.

OLIVEIRA JR., Wencesláo Machado de. A educação visual dos mapas. Revista Geográfica de América Central. Costa Rica: Número Especial EGAL, p. 1-16, 2011. 
OLIVEIRA JR., Wencesláo Machado de. Mapas em deriva: imaginação e cartografia escolar. Revista Geografares, n.12, p. 01-49, 2012.

PALSKY Gilles. Map design vs. Semiologie graphique. Reflections on two currents of cartographic theory. In: INTERNATIONAL CARTOGRAPHIC CONFERENCE, 25, 2011. Paris, Proceedings 25 ICC, Paris, 2011. CD-ROM.

PERKINS, Chris; DODGE, Martin; KITCHIN, Rob. Introductory essay: Cartographic aesthetics and map design. In: (Eds.) The map reader: theories of mapping practice and cartographic representation. Londres: Wiley, s. 3, cap. 3.1, p. 194-200. 2011.

PETCHENIK, Barbara B. A map maker's perspective on map design research 19501980. In: TAYLOR, D.R.F. (Ed.). Graphic communication and design in contemporary cartography. New York: J. Wiley \& Sons, v. II, cap.1, p. 37-68. 1983.

SEEMANN, Jörn. Regional narratives, hidden maps, and storied places: cultural cartographies of the Cariri region, Northeast Brazil. 2010, 342 p. Tese (Doctor of Philosophy) - Louisiana State University.

SIMIELLI, Maria Elena Ramos. O mapa como meio de comunicação: implicações no ensino de geografia do $1^{\circ}$ grau. 1986, 205 p. Tese (Doutorado em Geografia Física) Faculdade de Filosofia, Letras e Ciências Humanas, Universidade de São Paulo.

WATSON, Ruth. Mapping and contemporary art. The Cartographic Journal, v. 46, n. 4, p. 293-307, 2009.

WOOD, Denis. Map art, Cartographic Perspectives, n. 53, p. 5-14, 2006.

WOOD, Denis. Rethinking the power of maps. New York: The Guilford Press, 2010. $335 \mathrm{p}$.

Recebido em 10/07/2017.

Aceito em 12/09/2017.

Publicado em 02/01/2018. 